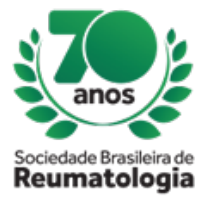

\title{
THE MOMENT OF PALLIATION IN RHEUMATOLOGY: REPORT OF FIVE CASES
}

ANA CLARA RIBEIRO (HSPE - IAMSPE, São Paulo, SP, Brasil), ANDRE OZELA AUGUSTO (HSPE - IAMSPE, São Paulo, SP, Brasil), NATALIA CARNEIRO DOS SANTOS (HSPE - IAMSPE, São Paulo, SP, Brasil), ESTEVÃO COSTA SANTANA (HSPE - IAMSPE, São Paulo, SP, Brasil), SONIA MARIA ALVARENGA ANTI LODUCA LIMA (HSPE - IAMSPE, São Paulo, SP, Brasil), NAFICE COSTA ARAUJO (HSPE - IAMSPE, São Paulo, SP, Brasil), RINA DALVA NEUBARTH GIORGI (HSPE - IAMSPE, São Paulo, SP, Brasil)

\section{BACKGROUND}

Despite the limitations in the treatment and severity of some systemic manifestations in Rheumatologic diseases, Palliative Care (PC) have been uncommonly incorporated in usual practice, and as a consequence, there are few publications regarding the theme. The therapeutic arsenal is evolving, bringing longevity to patients, although not always with quality of life, some patiens live with poorly controlled dyspnea and pain.

Since 2015, patients from this Reference Center with no prospects of therapy progression, are referred to the PC team, after joint resolution with the patient, relatives and the Rheumatology service. We briefly report patients with advanced rheumatologic diseases.

\section{CASE REPORT}

Case 1: Male, Systemic Sclerosis (SE) diagnosed in 1998 at age 58, with interstitial lung disease (ILD) and pulmonary arterial hypertension (PAH). Domiciliar oxygen user (O2) since 2007. With progressive dyspnea, progressing to right heart failure secondary to PAH. In 2015, he was referred to the CP group, using morphine for dyspnea, and conforting the family. Dies in 2018, at age 78.

Case 2: Female, Rheumatoid Arthritis (RA) diagnosed in 1982 at age 32. She presented cervical compressive myelopathy, with a C5-C6 arthrodesis in 2003 to attempt symptom control. Presented with surgical dehiscence with refractory cervicalgia. Initiated follow-up with PC in 2016, maintained with methotrexate $7.5 \mathrm{mg} /$ week and prednisone $5 \mathrm{mg}$ and use of fentanyl for pain control. She was bedridden for 3 years with food and infection support. Passed away in 2019, at the age of 69.

Cases 3 and 4: females, SE, diagnosed in 1999, at 40 years and in 2005 at 30 years, with ILD and PAH. Dyspnea clinic, 02 users 1 year ago. Follow-up with PC since 2018 starting the use of morphine.

Case 6: Male, Ankylosing Spondylitis diagnosed in 2007 at age 66, with cervical spinal canal stenosis by syndesmotic compression leading to dysphagia. Initiated follow-up with PC about 6 months ago, with gastrostomy for feeding and methadone for pain control. Living in a nursing home.

\section{CONCLUSION}

This experience has shown a great comprehension of those involved regarding their disease stage, and provided comfort in the following-up of patients in the terminal stage, according to the Advanced Care Planning from the PC referrals.

As clinicians and Rheumatologists, we must be empowered to provide not only medications, but actual care for patients, and understand that the end of life is also an important moment in the patients' life, respecting their needs and wishes. 